\title{
Impact of early psychosocial factors (childhood socioeconomic factors and adversities) on future risk of type 2 diabetes, metabolic disturbances and obesity: a systematic review
}

Teresa Tamayo $^{1 *}$, Christian Herder ${ }^{2}$, Wolfgang Rathmann ${ }^{1}$

\begin{abstract}
Background: Psychological factors and socioeconomic status (SES) have a notable impact on health disparities, including type 2 diabetes risk. However, the link between childhood psychosocial factors, such as childhood adversities or parental SES, and metabolic disturbances is less well established. In addition, the lifetime perspective including adult socioeconomic factors remains of further interest.

We carried out a systematic review with the main question if there is evidence in population- or community-based studies that childhood adversities (like neglect, traumata and deprivation) have considerable impact on type 2 diabetes incidence and other metabolic disturbances. Also, parental SES was included in the search as risk factor for both, diabetes and adverse childhood experiences. Finally, we assumed that obesity might be a mediator for the association of childhood adversities with diabetes incidence. Therefore, we carried out a second review on obesity, applying a similar search strategy.
\end{abstract}

Methods: Two systematic reviews were carried out. Longitudinal, population- or community-based studies were included if they contained data on psychosocial factors in childhood and either diabetes incidence or obesity risk.

Results: We included ten studies comprising a total of 200,381 individuals. Eight out of ten studies indicated that low parental status was associated with type 2 diabetes incidence or the development of metabolic abnormalities. Adjustment for adult SES and obesity tended to attenuate the childhood SES-attributable risk but the association remained. For obesity, eleven studies were included with a total sample size of 70,420 participants. Four out of eleven studies observed an independent association of low childhood SES on the risk for overweight and obesity later in life.

Conclusions: Taken together, there is evidence that childhood SES is associated with type 2 diabetes and obesity in later life. The database on the role of psychological factors such as traumata and childhood adversities for the future risk of type 2 diabetes or obesity is too small to draw conclusions. Thus, more population-based longitudinal studies and international standards to assess psychosocial factors are needed to clarify the mechanisms leading to the observed health disparities.

\section{Background}

In adults, adverse psychosocial factors such as low socioeconomic status (SES), deprivation and traumata have been shown to be associated with type 2 diabetes

\footnotetext{
* Correspondence: teresa.tamayo@ddz.uni-duesseldorf.de

'Institute of Biometrics and Epidemiology, German Diabetes Center, Leibniz Center for Diabetes Research at Heinrich-Heine-University, Düsseldorf, Germany

Full list of author information is available at the end of the article
}

[1], obesity [2-5], cardiovascular disease [6,7], and unhealthy lifestyle habits [8-11]. A lower social status is related to higher stress levels [12] and poor living conditions [13], which may partly explain these associations. Health disparities can be observed fairly early with lower birth weights, an earlier adiposity rebound and higher rates of infant mortality in the low SES groups [14-16]. 
Data on the association of type 2 diabetes and adverse childhood circumstances is more limited [17]. In two cross-sectional analyses there was evidence that adverse social conditions in childhood are independently associated with an increased risk of metabolic impairments and insulin resistance $[18,19]$. In a Swedish populationbased study, Agardh et al. found low parental education, low family household income and low parental occupational position to be associated with a more than twofold increased diabetes risk in adulthood, which was attenuated after accounting for adult socioeconomic factors [20].

Thus, the primary aim of this review was to evaluate the risk of psychosocial factors on type 2 diabetes incidence and the role of change in socioeconomic conditions throughout life on the basis of population-based and longitudinal studies. As several factors of childhood environment are closely related and interact with each other [21], we aimed not only to address the relationship of childhood socioeconomic status (CSES) with diabetes incidence, but to investigate a broad range of psychosocial factors. Furthermore, obesity was included as it is considered a key factor for diabetes incidence in youth and as it is also influenced by SES [22]. Since a first comprehensive review [23] on the inverse relationship between SES and obesity in developed countries, these early results have been substantiated in further systematic reviews $[2,4]$. We included obesity as endpoint in our review and concentrated on longitudinal and population-based studies with particular focus on the analysis of change in weight status and psychosocial circumstances.

\section{Methods}

\section{Search criteria}

We searched Medline in July 2008 and carried out an update of the search in April 2010 applying the search algorithm "(diabetes or insulin resistance or prediabetes or metabolic syndrome) and (SES or social or socioeconomic or psychosocial or income or working status or migration or community or adversities or deprivation or depression or abuse or high risk family or hostility)".

For obesity a search in Medline was carried out in November 2008 (updated in April 2010) using the algorithm" (obesity or overweight) and (socioeconomic or social or deprivation or adversities or childhood socioeconomic or family environment or early life or youth or childhood adversities or deprivation) and (longitudinal or prospective or cohort)".

Both searches were limited to publications after 31 December 1994 in English language. During the 1990 s, the diabetes criteria were changed several times, which complicates comparison with earlier publications.

\section{Inclusion and exclusion criteria}

Studies were included if incident cases of type 2 diabetes were assessed. Cross-sectional studies with data on diabetes prevalence only were excluded. Only populationor community-based studies were included to have a more homogeneous database for this review. Further outcome criteria were insulin resistance, elevated HbA1c values, and the metabolic syndrome because they share risk factors and pathophysiological pathways with type 2 diabetes. Obesity and overweight are considered key risk factors for type 2 diabetes incidence especially in youth, and were furthermore included as outcome parameters, but were analysed separately.

\section{Risk factor specification: Childhood psychosocial factors}

Studies on incident type 2 diabetes or obesity were included if they contained data on psychosocial factors including a wide range of indicators reflecting the social and psychological conditions under which the participants grew up:

(1) basic indicators of CSES: parental education; parental occupation and family income as indicators of economic wealth and stability;

(2) further indicators of wealth and deprivation: public housing, housing conditions, house ownership, unemployment;

(3) the high-risk family concept (adverse childhood experiences) regarding neglect, abuse and household dysfunction [24];

(4) indicators of impaired psychological health in children such as depression or anxiety;

(5) indicators of the ability to cope with stressful conditions like coping skills or sense of control [25];

(6) indicators of possibly stressful situations: migration, parental stress (e.g. stressful working conditions or parenting stress which are supposed to have implications for children's stress as well);

(7) neighbourhood deprivation indexes as indicator for the aggregation of unfavourable circumstances clustered in residential areas. These indexes are based on the social composition of neighbourhoods regarding for example the social status of its habitants, housing and street conditions, mean household sizes per person and other indicators of wealth such as mean household number of cars $[26,27]$.

Studies were excluded if information on obesity and overweight was only available at one time point and no adjustment for previous weight status was done. Studies, which only included type 1 diabetes were also excluded. Self-reported diabetes type may not offer a reliable distinction between the diabetes mellitus types. However, self-reported diabetes type was found in most studies and as type 1 diabetes contributes to a fairly small 
proportion of the total number of diabetes cases we accepted self-reported diabetes type for the assessment of type 2 diabetes incidence.

\section{Data extraction and quality management}

Eligible studies were assessed by one reviewer (T. T.) and discussed with a second reviewer (W. R.). The final list of variables extracted from the selected studies contained the first author, publication year, country where the study was carried out, cohort size, study duration, age characteristics of participants, measurement of risk factors, definition of diabetes/obesity variables and a brief description of results including effect size. For missing information we contacted some of the authors of the selected studies. Any disagreements regarding numbers, study inclusion, and further analysis were resolved by consensus between the authors (T.T., C.H., W.R.).

\section{Analysis and quality assessment}

We restricted the analysis to descriptive measures because of the lack of statistical comparability for most studies. Effect sizes extracted from the publications reflect adjusted results for odds ratio (OR), hazard ratio (HR) and relative risk (RR) regarding confounding (1) for age, sex, BMI, physical activity, smoking and alcohol (for type 2 diabetes incidence) or (2) for birth weight and adult SES (for obesity and overweight). We developed a 5 item quality scale adapted to our purpose with reference to methodological recommendations of the Meta-analysis Of Observational Studies in Epidemiology (MOOSE) group $[28,29]$. The sum score derived from this scale mainly had to reflect the study design, the examined outcome parameters, the risk factor construction and the control for confounders. Quality was judged taking into account the current state of research on type 2 diabetes and obesity and possible sources of bias. The following criteria were included into the quality score for the (1) diabetes and (2) obesity studies:

- (1\&2) Study Duration (D): Highest quality was considered to be obtained from birth cohorts $(D=1)$ as the future diabetes and obesity risk is influenced strongly by very early health indicators such as birth weight and gestational age. Furthermore, especially in childhood body composition and metabolic functioning vary in different age groups, so that homogeneous age groups as accomplished by birth cohort studies offer another quality advantage $[30,31]$.

- (1\&2) Recruitment (R): Our inclusion criteria comprised only studies from which a high grade of representativeness and reproducibility was expected. To further assess the quality of recruitment in the score, population-based or school-based studies with characteristics of a census were rated as of highest quality $(R=1)$.
- (1\&2) Explanatory variables/risk factor specification (E): We expected a source of bias from retrospectively assessed childhood psychosocial factors in the offspring $(\mathrm{E}=0)$. In case parents gave direct information on their occupational, educational and financial situation we rated the quality of risk factor construction as high $(\mathrm{E}=1)$.

- (1) Outcome parameter diabetes: Highest evidence was expected from blood glucose measurements with internationally valid cut off-levels as defined by the American Diabetes Association or WHO $(\mathrm{O}=1)$ [32]. Self-reported diabetes leads to an underestimation of type 2 diabetes cases due to a high number of undiagnosed cases $[33,34]$. Therefore, we considered the quality based on self-report as low $(\mathrm{O}=0)$. The plasmabased measure of insulin resistance (HOMA-IR calculated from fasting glucose and insulin levels) is closely related to (pre)diabetes. Thus, evidence from HOMAIR-based data were considered as high $(\mathrm{O}=1)$. Although HbA1c has been suggested as diagnostic tool for type 2 diabetes (ADA 2010), especially in early diabetes and in prediabetes, $\mathrm{HbA1c}$ values lead to misinterpretation which may be also due to a genetic component in the metabolisation of glycated haemoglobin [35-39]. Thus, we rated the quality of HbA1c values as low $(\mathrm{O}=0)$. Metabolic syndrome and type 2 diabetes share some risk factors, but are too different as entities to include the metabolic syndrome as surrogate for type 2 diabetes. We allowed for the term 'metabolic' during Medline search, but rated metabolic syndrome as outcome criteria of low evidence for our study question $(\mathrm{O}=0)$.

- (2) Outcome parameter obesity (O): First, measured weight and height to calculate BMI met our quality demands. Self-reported weight and height on the other hand have been reported to be imprecise in adults and in parents reporting anthropometric data of their children. Standard cut-off values for overweight and obesity served as second indicator for high quality: In children overweight and obesity are defined based on the age and sex-specific $85^{\text {th }}$ and $95^{\text {th }}$ BMI percentiles in growth charts from the National Health and Nutrition Examination Survey (NHANES), the Centers for Disease Control and Prevention (CDC) or the International Obesity Taskforce (IOTF), whereas in adults cut-off values for BMI $\geq 25 \mathrm{~kg} / \mathrm{m}^{2}$ for overweight and $\geq 30 \mathrm{~kg} / \mathrm{m}^{2}$ for obesity were used. The highest score $(\mathrm{O}=1)$ was given only if both criteria were fulfilled.

- (1\&2) Confounding (C): Quality of adjustment for confounders was inferred from important behavioural pathways leading to type 2 diabetes. Adjustment of age, sex, BMI, smoking, physical activity and alcohol consumption was required for the highest quality score $(C=1)$. Adjustment for obesity in the extracted studies 
was heterogeneous and depended highly on the study question. According to the basic requirements for our review question a high study quality $(\mathrm{O}=1)$ demanded at least control for birth weight or baseline BMI to have possible weight change considered and the adjustment for adult SES to control SES change throughout life.

\section{Results}

\section{Identification of relevant studies}

The search strategy yielded a total of 19,504 results. After exclusion of 5,537 non-English articles, reviews, animal studies, case reports and articles unrelated to type 2 diabetes, 13,967 abstracts were screened (see also Figure 1). We assumed that social parameters are often treated as confounders and in this case the results are presented in full text articles, but not in abstracts. Therefore, the first screening of abstracts served mainly to identify articles on diabetes incidence (591). Of these, 280 did not meet the study design criteria and were excluded. The further thematic evaluation of the psychosocial relevance of the studies was based on full text articles. Of these 273 were thematically irrelevant mainly because they did not offer information on childhood psychosocial factors. One study retrieved during the update of the search was not added, because it presented race stratified results and there was already nonstratified data available from this study from the first search [40].

For reasons of limited statistical comparability (p.eg. limited presentation of data) 10 studies remained for further descriptive analysis (Table 1). Information on excluded studies with a unique method of analysis such as path models is provided in the discussion, information on excluded studies with solely examined risk factors in the results.

The second search strategy for the outcome obesity retrieved 1,631 results (see also Figure 1). 77 reviews and non-English publications were excluded. 1,428 studies were classified as thematically irrelevant and 76 publications did not meet study design criteria. This led to 50 longitudinal studies of which 36 were not comparable for methodological reasons and risk factor selection. Hence, 14 publications (13 studies) were included for this review and are presented in Table 2.

\section{Description of included studies: diabetes incidence Study design}

Five publications involving 9,200 cases of incident diabetes were included [41-45]. Furthermore, we identified 147 cases of insulin resistance [46], 953 cases of elevated HbA1c [47,48] and 233 cases of "metabolic malfunctioning" [49] in a total of 199,214 individuals. One study analysed HOMA-IR as continuous variable in 1,167 individuals, but did not present the number of cases with insulin resistance [50]. Hence, overall 10 studies are summarised in Table 1. Four studies were designed as birth cohorts [43,47-49], two were conducted in children or adolescents (age range 3-18 and 14-19 years, respectively) $[46,50]$. All other studies measured childhood psychosocial factors retrospectively mainly in middle-aged participants.

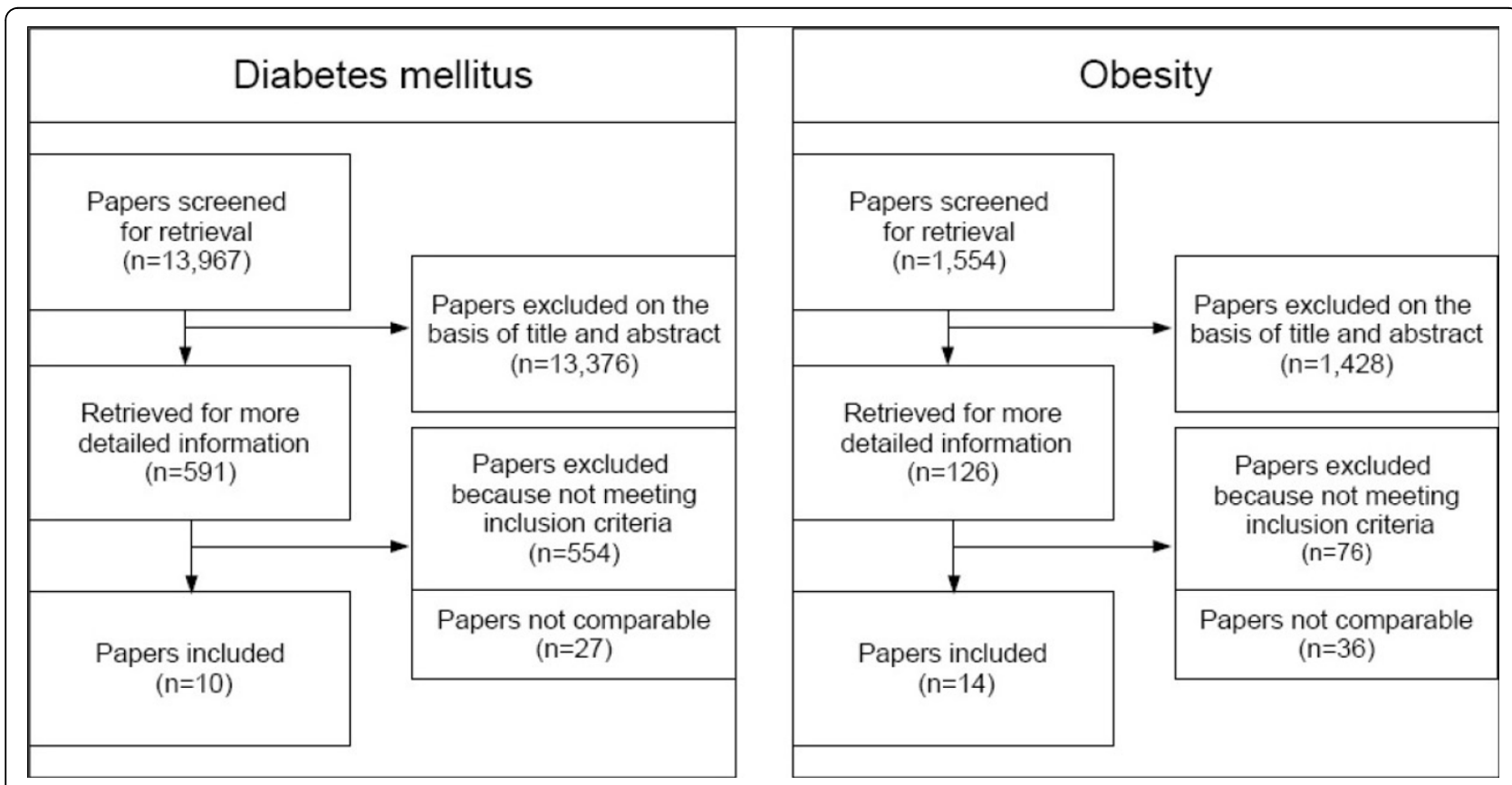

Figure 1 Flow diagram of systematic review on type 2 diabetes incidence and on obesity 


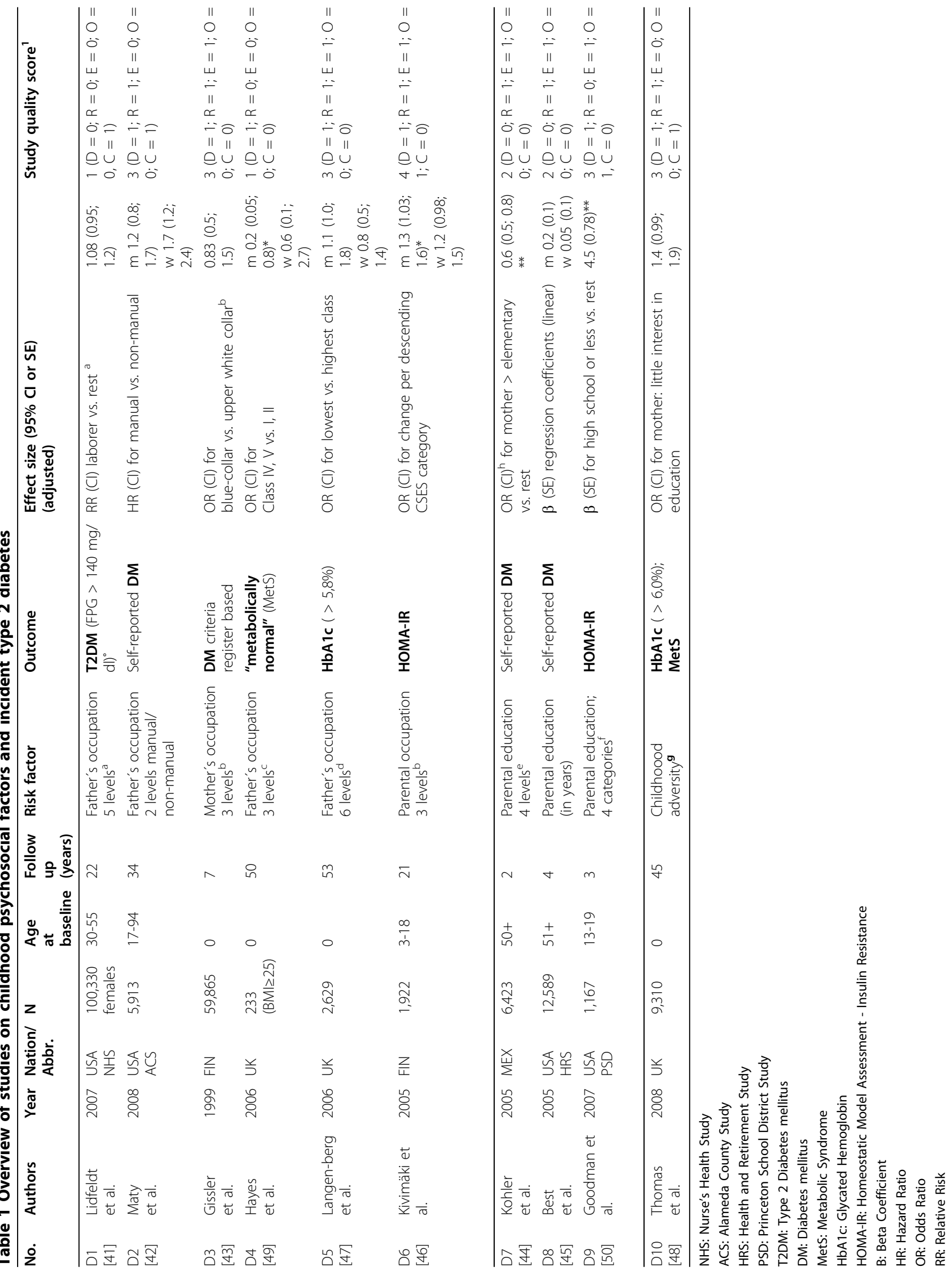




\section{Psychosocial factors}

Most of the articles provide data of parents' occupation as basic indicator variable for socioeconomic status (Table 1). Parental education was offered as main SES risk factor in three other studies. However, both SES variables were heterogeneously defined in these studies. Parents' occupation, for instance, was measured in five different classification scales ranging from two to six levels and following three different classification standards [51-53]. Childhood adversity as risk factor was found in one study only [48]. In this study, little parental interest in education was assessed as one aspect of emotional neglect. As this item might be related to formal parental education as well, results are presented in Table 1.

\section{Outcomes}

Self-reported diabetes was the most common outcome measure without restriction to type 2 diabetes. Only one article by Lidfeldt et al. was completely concordant with our review question by defining type 2 diabetes incidence on the basis of fasting plasma glucose levels according to ADA recommendations in an originally diabetes-free cohort [41]. HbA1c levels above $5.8 \%$ and $6.0 \%$ were used in two studies to define metabolically abnormal cases $[47,48]$. Insulin resistance according to HOMA-IR levels above 5.8 and 6.0 was the outcome parameter in two more studies $[46,50]$. One study defined "metabolically normal" cases following the definition of metabolic syndrome from the International Diabetes Federation, but without weight indicators because only participants with $\mathrm{BMI} \geq 25 \mathrm{~kg} / \mathrm{m}^{2}$ were included [49].

\section{Description of included studies: Overweight and obesity Study design}

Thirteen studies met the inclusion criteria for obesity as outcome parameter adding up to a sample size of 70,420 participants with mainly young age groups ranging from 0-19 years. One study included middle-aged persons from 40-60 years and retrospectively assessed paternal occupation [54]. Overall, the study durations ranged from 4-33 years (median: 13 years), five studies were designed as birth cohorts [55-59].

\section{Psychological factors}

The risk factor definition among the obesity studies was similarly heterogeneous as in the diabetes studies. Data on parental occupation was most frequently presented followed by parental education. Family income was additionally included to parental education in four studies [58,60-62]. In one study results on the Home Observation for Measurement of the Environment Short Form Inventory (HOME-SF), a questionnaire measuring emotional and cognitive family environment and parenting abilities, was presented $[61,63,64]$. 


\section{Outcomes}

In most studies the outcome regarding obesity and overweight was defined according to standard cut-off values based on BMI values calculated from measured height and weight $[54,56,58,60,61,65,66,68,69]$. Three studies deduced BMI from self-reported anthropometric measures $[55,62,67]$. One study analysed dual-energy X-ray absorptiometry (DXA)-assessed fat mass [59]. Obesity incidence was determined only in the National Longitudinal Survey of Youth [61]. One study analysed age at onset of obesity and in a later publication also weight change, but without exclusion of cases with obesity at baseline $[62,68]$. Analysis of weight change over time was also done in three other studies $[58,65,67]$.

\section{Diabetes incidence: Effect of childhood socioeconomic factors}

In four studies, the risk of developing type 2 diabetes or metabolic disturbances in the offspring of lower social classes compared to children of higher status was only slightly elevated after adjustment with different effect measures (OR, HR and RR) ranging between 1.08 and $1.7[41,42,46,48]$. In the Alameda County Study, disparities in self-reported diabetes were most striking in overweight women with low childhood socioeconomic position [42]: The odds of developing type 2 diabetes was 3.2 fold higher for them than for their high SEP counterparts (OR: 2.9 (95\% CI 1.7; 4.8) vs. 0.9 (95\% CI $0.4 ; 2.2)$ ).

As shown in Table 1, the study with the smallest population size $(\mathrm{N}=233)$ showed the largest protective effect (men OR 0.2 (95\% CI 0.05, 0.8); women 0.6 (0.1, 2.7)) of a high social status (father's occupation) [49]. This study was based on middle-aged participants of the Newcastle Thousand Families Cohort with a BMI exceeding $25 \mathrm{~kg} / \mathrm{m}^{2}$. Furthermore a large protective effect of maternal education (beyond elementary level) was found in a Mexican population (OR 0.6 (95\% CI $0.5 ; 0,8)$ [44]. In contrary, low maternal education at high school level or less was a significant factor influencing type 2 diabetes incidence in the Princeton School District Study (ß-coefficient $=4.47$ (SE 0.78)).

On the other hand, two studies indicated small, nonsignificant protective effects of low social class. In a Finnish cohort children at the age of 7 years from bluecollar families had a reduced risk (OR 0.8 (95\% CI 0.48; 1.45) of being diagnosed with type 2 diabetes in comparison with their white-collar counterparts [43]. In a British Cohort only women of the lowest classes were less likely to have HbA1c levels exceeding 5.8\% (OR 0.8 $(95 \%$ CI $0.5 ; 1.4))$. In men, no effect of social class was seen in this study (OR 1.1 (95\% CI 1.0; 1.8)) [47].

The effect sizes observed in the included studies (except for beta coefficients) are shown in Figure 2.
Effects of high social status have been inverted for better visual comparability.

\section{Diabetes incidence: Change in socioeconomic factors from childhood to adulthood}

Furthermore, we were interested in the interaction of childhood and adult psychosocial variables. SES change was explicitly examined in the Nurses Health Study [41]. Participants in this study were relatively homogeneous with respect to their educational level and occupational status as all 100,330 participants were female nurses. Disparities emerged from different childhood socioeconomic positions and from husband's educational level. Improving SES over lifetime (spouse's high educational level and low father's occupational status) with stable high SES as reference resulted in a slightly reduced, albeit non-significant relative risk for type 2 diabetes (RR 0.9 (95\% CI 0.7; 1.3), whereas a stable intermediate SES and a declining SES influenced the type 2 diabetes relative risk negatively (RR 1.2 (95\% CI $1.06 ; 1.4)$ and RR 1.18 (95\% CI 1.06; 1.3), respectively). The relative risk in participants with stable low SES was comparable to those participants with stable high SES.

Langenberg et al. examined lifetime effects by analysing the change in the influence of the socioeconomic position on HbA1c levels with adjustment for childhood and adult SEP [47]. In both men and women, adult social class had stronger effects than childhood social class on HbA1c values exceeding 5.8\%. In women childhood effects on $\mathrm{HbA1c}$ even reversed in the fully adjusted model. Langenberg et al. interpret these findings by postulating that low childhood social class continues to influence adult social class as both variables were highly correlated [47].

A high continuity of childhood and adult SEP parameters was also observed in a Finnish cohort, where children from manual classes were more likely to work in manual or lower non-manual occupations in adulthood [46].

\section{Diabetes incidence: Effect of other psychosocial factors}

Among the retrieved studies there were several unique findings that were not comparable with other studies and other results. However, most of these studies revealed a possible association with future diabetes.

For example psychological factors such as childhood adversities [48] were associated with elevated HbA1c and obesity in one study. After full adjustment, these associations were no longer significant for elevated HbA1c. A further possible psychological risk factors for diabetes among our findings were depression and anxiety [70,71], hostility [72], and sense of coherence [73].

Also, indirect measures of socioeconomic status such as deprived neighbourhoods, and housing conditions 


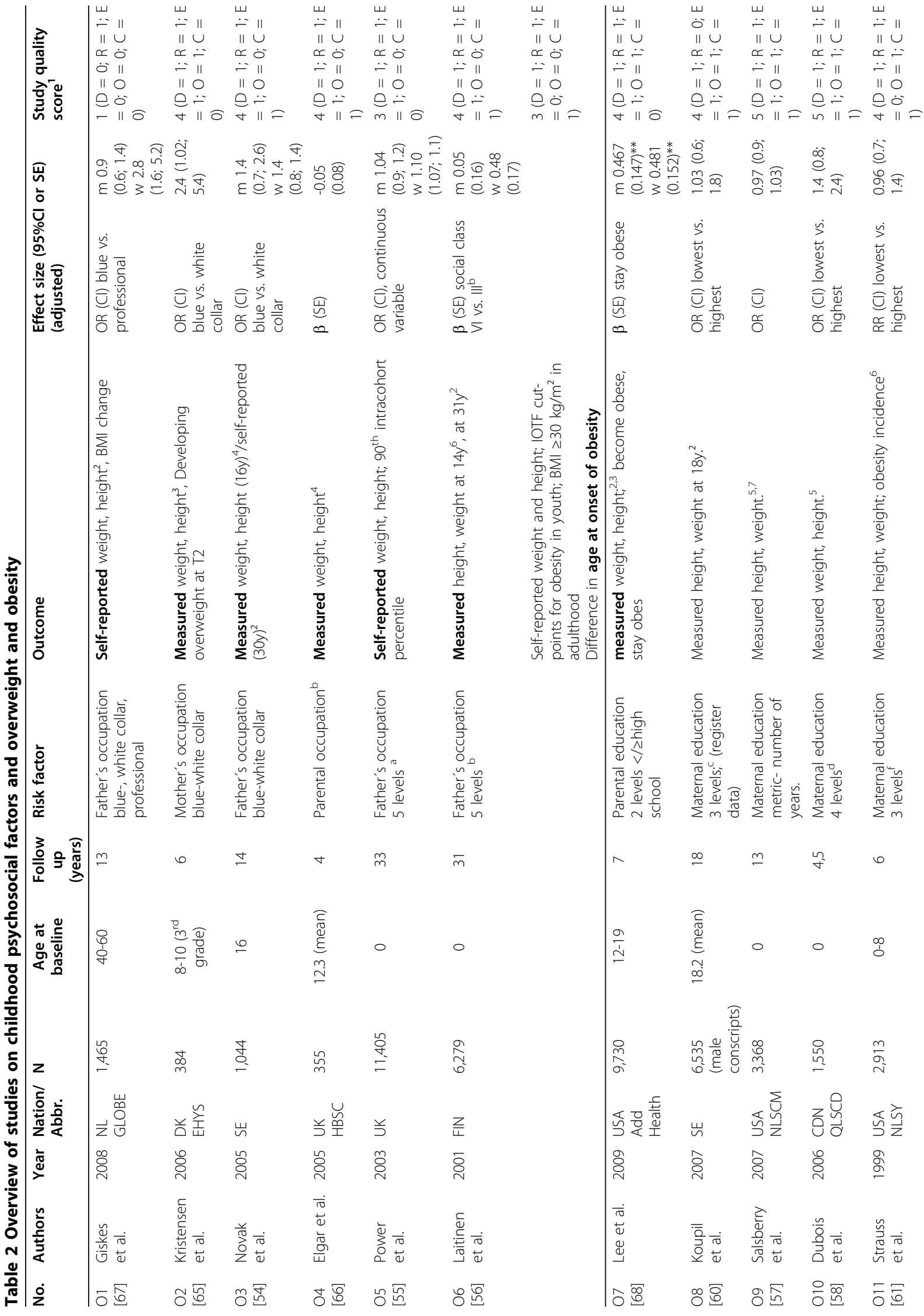




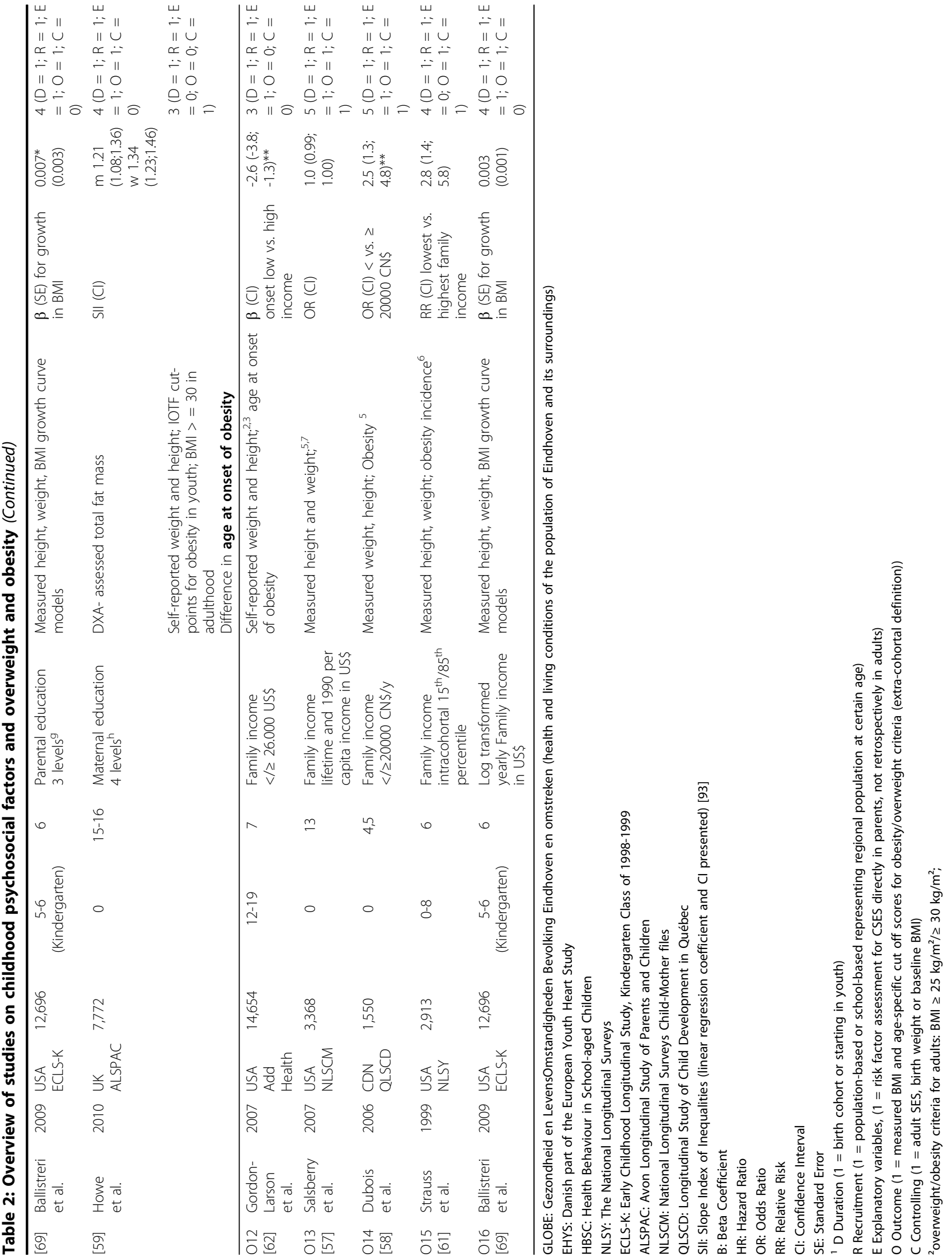


$[27,28,74,75]$ are likely to be relevant for future diabetes incidence. Neighbourhood characteristics also have influence on lifestyle habits depending e.g. on the availability of healthy foods and on the number of facilities for physical activity [76].

Overall, more comparable studies are needed to quantify the association of other childhood factors on metabolic impairment.

\section{Overweight and obesity: Effect of childhood socioeconomic factors}

Table 2 gives an overview of the included studies and the observed effect sizes which are furthermore visualised in Figure 3.

Effects were most prominent in two studies regarding income discrepancies: In a national longitudinal survey in the USA the RR in the lowest intracohortal $\left(<15^{\text {th }}\right.$ percentile) income group for obesity incidence was 2.84 (95\% CI $1.39 ; 5.78)$ compared to the highest $\left(>85^{\text {th }}\right.$ percentile) income group during 6 years after the baseline examination [61]. Similar results were observed in a Canadian birth cohort at the follow-up of 4.5 years [58]. At that time point the lowest income group (less than $20,000 \mathrm{CN} \$$ /year) had a 2.5 fold increased odds (95\% CI $1.3,4.8)$ of being overweight at the age of 4.5 years with reference to families with an annual income of 60,000 $\mathrm{CN} \$$ or more. These results were obtained after adjustment for gestational age and birth weight. One study observed that belonging to a low income family (less than 26,000 US\$/year) was a significant predictor of being obese at an earlier age ( $\beta$-coefficient: -2.6 (95\% CI $-3.8 ;-1.3)$ ) [62]. No effect of family income was seen in another study which included data from the National Longitudinal Surveys Child-Mother files in the USA (OR 1.0 (95\% CI 0.99, 1.00)) [57].

Parental education had no direct or a small influence on overweight or obesity outcomes in six studies $[57,58,60,61,68,69]$. In the National Longitudinal Survey of Youth [61], the Home Observation for Measurement of the Environment-Short Form (HOME-SF) accounted for a modulation of other CSES factors particularly for maternal education. The unadjusted OR for the six-year cumulative incidence of childhood obesity for maternal education lower than high school was 1.47 (95\% CI $1.04 ; 2.1$. The fully adjusted OR was lowered to 0.96 $(95 \%$ CI 0.7 ; 1.4) when including also HOME-SF as covariable. In contrast, family income seemed to be independent of the HOME-SF in this study [61].

In one study regarding parental occupation gender disparities were prominent [67]. Giskes et al. found a significantly higher risk for baseline overweight and obesity (at 40-60 years) for female participants whose fathers had been working in blue-collar occupations (OR 3.4 (95\% CI $1.9 ; 6.1)$, father's professional 


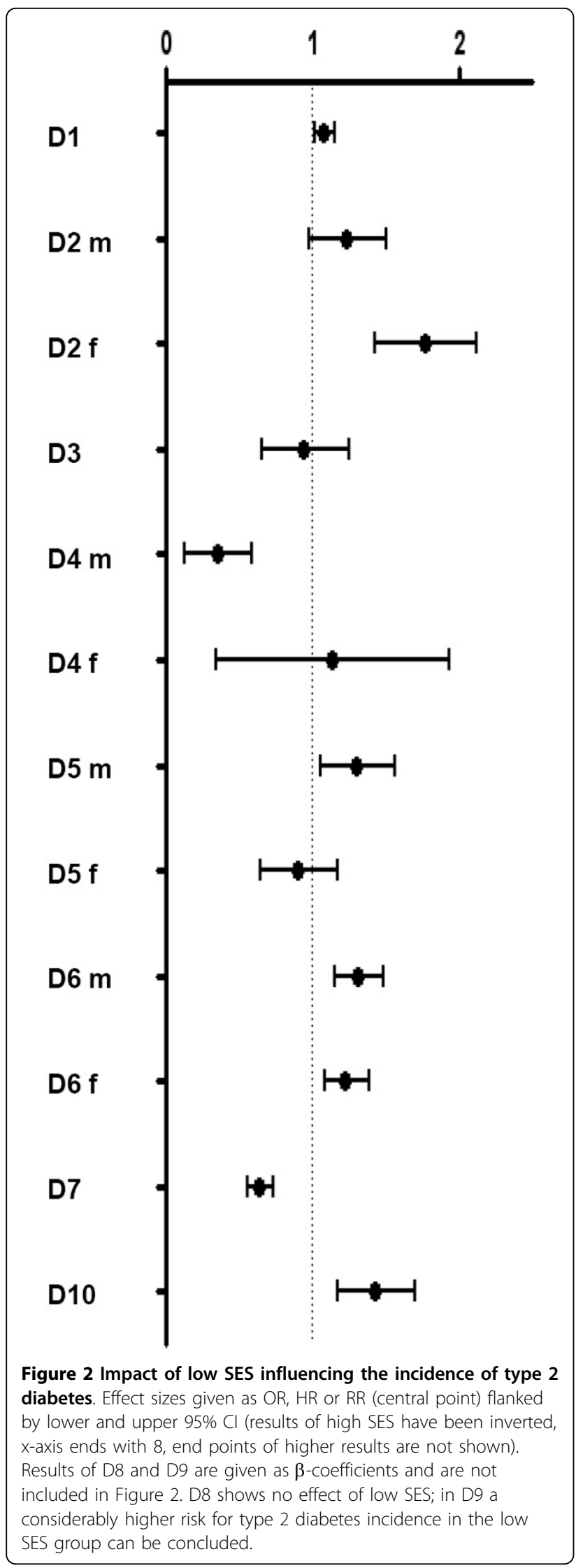

occupation as reference). This effect decreased slightly after adjustment for adult SES (OR 2.8 (95\% CI 1.6; $5.2)$ ). These women also gained significantly more weight between baseline and follow-up 13 years later (OR 2.0 (95\% CI 1.7; 2.3)). In another study the risk for developing overweight during the 6-year follow-up period was increased for children from blue-collar families (OR 2.4 (95\% CI 1.02; 5.4) in comparison with their white-collar counterparts [65]. Furthermore, in two studies the adjusted effects of low status were small $[54,55]$.

Based on results of regression analysis, two studies determined low social status as factor influencing overweight and obesity $[56,62]$, whereas in a third study no such effect was seen (ß-coefficient: -0.05 (SE 0.08)) [66]. In another study, DXA-assessed fat mass was analysed using a slope index of inequality (SII). The results of this method are comparable to regression coefficients and pointed towards a moderate association of maternal education on body fat [59].

However, as these studies only displayed data on regression coefficients, effect sizes cannot be compared to the other studies and are therefore not included in Figure 3.

Taken together, whenever effects were seen in any of the thirteen studies, they pointed towards a deleterious influence of low social status on future risk of overweight and obesity.

\section{Overweight and obesity: Effect of change in} socioeconomic factors from childhood to adulthood The role of change in psychosocial factors in relation to obesity was investigated in the 1958 British birth cohort [55]: Power et al. reported a continuous decrease of the effects of low socioeconomic status in childhood on obesity especially in women with an increase in social position in adulthood. The effect of low social class at the age of seven years in 33-year old women decreased from an unadjusted OR of $1.4(95 \%$ CI $1.3 ; 1.6)$ to 1.3 $(95 \%$ CI $1.1 ; 1.4)$ after adjustment for personal education [55].

\section{Overweight and Obesity: Effect of other psychosocial factors}

We found one study which showed that traumata are associated with obesity [77]. Furthermore, depression and stress [78] are not only relevant for type 2 diabetes, but also for obesity. Also, indirect measures of socioeconomic status such as deprived neighbourhoods, housing conditions [79] and supply for healthy lifestyle habits [80], are likely to be relevant for obesity.

Therefore, psychological factors, and several measures of deprivation in childhood remain an interesting field for further examinations helping to understand the 


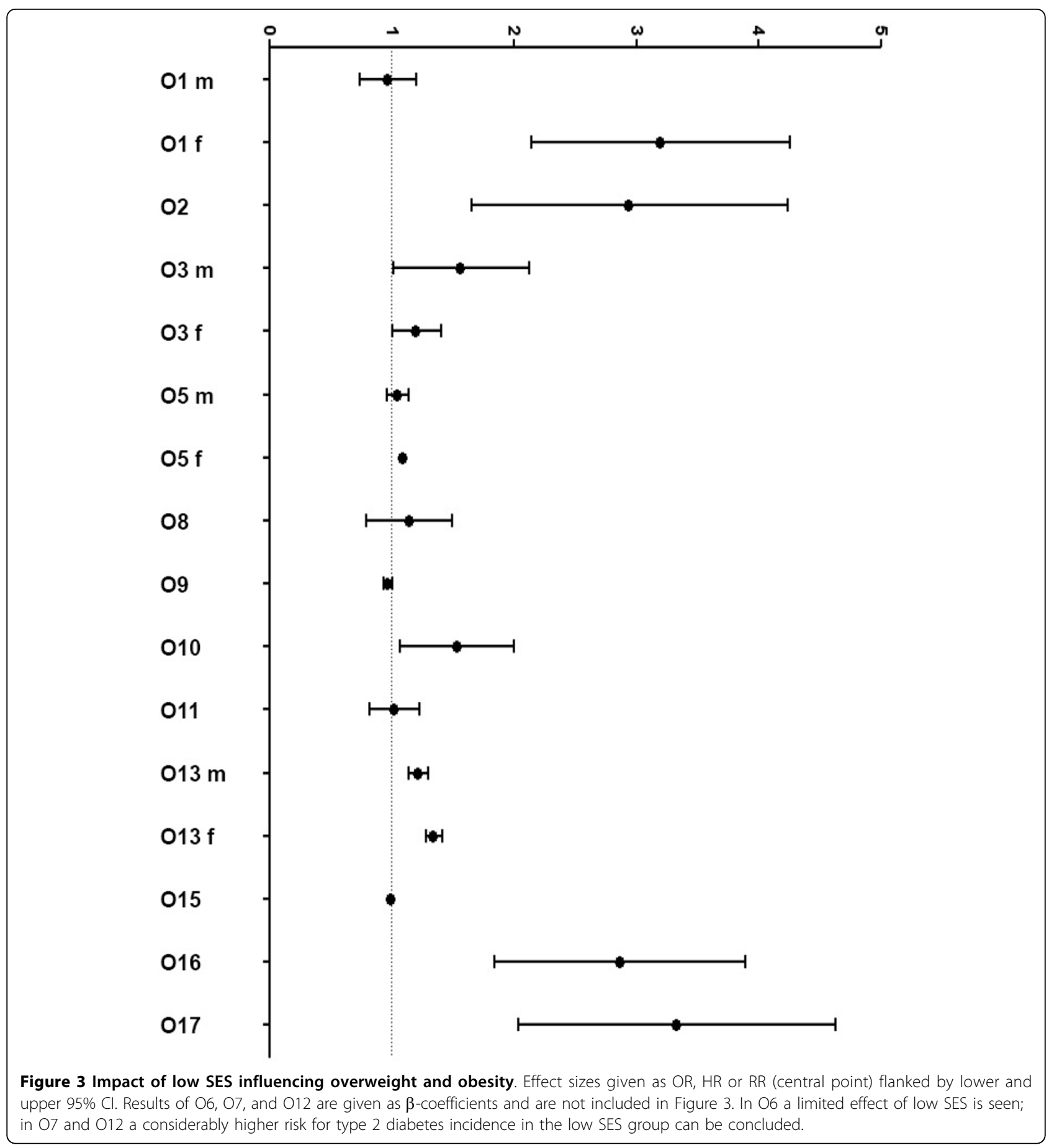

possible pathways leading to obesity and type 2 diabetes.

\section{Discussion}

Based on the included studies and bearing in mind the limited comparability, we can state that psychosocial discrepancies in childhood seem to have an unfavourable impact on future type 2 diabetes incidence. Adjustment for adult SES and BMI attenuated these associations considerably $[41,42,47]$. This finding raises the question if a favourable life course may be beneficial for the participants' metabolic status. However, detailed life course analysis was rarely carried out among the retrieved studies. Only one study offered indications that improving SES over time seems protective against diabetes and that a decrease in SES is especially harmful [41]. But as only one study provided substantial data on SES change, no valid conclusion can be drawn from these results. 
Furthermore, we found the family income $[67,58,61]$ and the father's occupation [[67], in women only; [65]] of relevance for overweight and obesity. Surprisingly, in contrast to our findings on diabetes incidence parental education seemed to have less impact on future obesity risk. However, lower parental education was linked to an earlier age at onset of obesity in one study [62].

\section{Limitations}

Altogether we observe that for both type 2 diabetes and obesity longitudinal, population-based data are scarce. Especially, the life course including childhood indicators of psychosocial status and the role of risk factor clustering is under-investigated. Additionally, analysis of psychosocial factors is carried out heterogeneously and thus exposed to the critique of constructing SES risk factors arbitrarily. Although there are some national consensus statements especially regarding the assessment of the occupational position [51-53], it is difficult to compare these positions because they are attributed with varying amounts of prestige and are influenced by general shifts in composition [81].

\section{Implications for research}

Three steps may help to gain further evidence on the topic: First, basic SES measures in youth and in adulthood should be consequently presented in publications. Second, for a better understanding of the role of psychosocial factors throughout life on the risk of type 2 diabetes, detailed analysis of a broad set of psychosocial factors, their interrelation and their impact on type 2 diabetes are needed. This requires a large-scale systematic analysis applying various psychosocial measures in youth and adulthood that have been found to be of relevance for diabetes and obesity such as depression [82-84], stress [85,86], unemployment [87], lifestyle habits $[76,80]$ deprived neighbourhoods $[27,28,74,75,79]$ and other factors $[72,77]$.

Finally, such a large-scale systematic analysis would also require the application of different analytic approaches. As an example, the interpretation of the results of regression models analysing closely related risk factors throughout lifetime is controversial. Attenuation after adjustment for various risk factors may be attributable to a strong correlation of these risk factors [22] rather than to confounding. An interesting alternative approach may be the analysis of path models. For example Lehman et al. showed that childhood SES had a direct impact on metabolic functioning in the participants by applying path models on data from the Coronary Artery Risk Development in Young Adults study (CARDIA). Furthermore, childhood SES had an impact on early family environment, psychosocial functioning and adult SES. Interestingly, adult SES in this study had no direct influence on metabolic functioning [88]. Additionally, cluster and discriminance analysis can shed further light on the interaction of a broad set of childhood and adult psychosocial indicators accounting also for highly differentiated social milieus with distinct beliefs, behaviours and tastes [89].

\section{Implications for practice}

Valid results on the association of childhood socio-economic circumstances and future risk of diabetes and obesity would be important to design targeted and more efficient prevention strategies. Diabetes and obesity prevention may not only profit from educational programmes but also from health politics, from interventions for high-risk families, from coping skills training [90], from empowerment of social networks and from healthy neighbourhoods $[91,92]$.

\section{Conclusion}

Taken together, despite the lack of homogeneous data, there is evidence for adverse effects of low psychosocial position in childhood on the risk for type 2 diabetes and obesity in later life. However, more studies and homogeneous standards regarding assessment of exposure and outcome variables and statistical analyses are needed.

\section{Acknowledgements}

The work is part of the Diabetes Competence Network including the DIABCORE (Collaborative Research of Epidemiologic Studies) Consortium which is funded by the German Ministry of Education and Research. Further support was obtained from The German Federal Ministry of Health and the Ministry of Innovation, Science, Research and Technology of the state North RhineWestphalia (Düsseldorf, Germany).

\section{Author details}

${ }^{1}$ Institute of Biometrics and Epidemiology, German Diabetes Center, Leibniz Center for Diabetes Research at Heinrich-Heine-University, Düsseldorf, Germany. ${ }^{2}$ Institute for Clinical Diabetology, German Diabetes Center, Leibniz Center for Diabetes Research at Heinrich-Heine-University, Düsseldorf, Germany.

\section{Authors' contributions}

WR and TT conceived the study aims and design. T, $\mathrm{CH}$ and WR contributed to the systematic review, data extraction, quality assessment and interpretation of the results. TT wrote the manuscript, supervised by $\mathrm{CH}$ and WR. All authors approved the final version of the manuscript.

\section{Competing interests}

The authors declare that they have no competing interests.

Received: 25 November 2009 Accepted: 1 September 2010 Published: 1 September 2010

\section{References}

1. Brown AF, Ettner SL, Piette J, Weinberger M, Gregg E, Shapiro MF, Karter AJ, Safford M, Waitzfelder B, Prata PA, Beckles GL: Socioeconomic Position and Health among Persons with Diabetes Mellitus: A Conceptual Framework and Review of the Literature. Epidemiol Reviews 2004, 26:63-77.

2. Parsons TJ, Power C, Logan S, Summerbell CD: Childhood predictors of adult obesity: a systematic review. Int J Obes Relat Metab Disord 1999, 23(Suppl 8):S1-107. 
3. Wang Y, Beydoun MA: The obesity epidemic in the United States-gender, age, socioeconomic, racial/ethnic, and geographic characteristics: a systematic review and meta-regression analysis. Epidemiol Rev 2007, 29:6-28.

4. McLaren L: Socioeconomic status and obesity. Epidemiol Rev 2007, 29:29-48.

5. Shrewsbury $V$, Wardle J: Socioeconomic status and adiposity in childhood: a systematic review of cross-sectional studies 1990-2005. Obesity (Silver Spring) 2008, 16(2):275-284.

6. Hemingway $\mathrm{H}$, Marmot M: Evidence based cardiology: psychosocial factors in the aetiology and prognosis of coronary heart disease. Systematic review of prospective cohort studies. BMJ 1999, 318(7196):1460-1467.

7. Blane D, Hart CL, Smith GD, Gillis CR, Hole DJ, Hawthorne VM: Association of cardiovascular disease risk factors with socioeconomic position during childhood and during adulthood. BMJ 1996, 313(7070):1434-1438.

8. Kvaavik E, Lien N, Tell GS, Klepp Kl: Psychosocial predictors of eating habits among adults in their mid-30s: the Oslo Youth Study follow-up 1991-1999. Int J Behav Nutr Phys Act 2005, 2:9.

9. Osler M, Madsen M, Nybo Andersen AM, Avlund K, McGue M, Jeune B, Christensen K: Do childhood and adult socioeconomic circumstances influence health and physical function in middle-age? Soc Sci Med 2009, 68(8):1425-1431.

10. Mackenbach JP, Stirbu I, Roskam AJ: Socioeconomic inequalities in health in 22 European countries. N Engl J Med 2008, 358(23):2468-2481.

11. Lawlor DA, Davey Smith G, Ebrahim S: Life course influences on insulin resistance: findings from the British Women's Heart and Health Study. Diabetes Care 2003, 26(1):97-103.

12. Meyer $I H$, Schwartz S, Frost DM: Social patterning of stress and coping: does disadvantaged social statuses confer more stress and fewer coping resources? Soc Sci Med 2008, 67(3):368-379.

13. Connolly V, Unwin N, Sherriff P, Bilous R, Kelly W: Diabetes prevalence and socioeconomic status: a population based study showing increased prevalence of type 2 diabetes mellitus in deprived areas. J Epidemiol Community Health 2000, 54(3):173-177.

14. Lynch JW, Kaplan GA, Cohen RD, Kauhanen J, Wilson TW, Smith NL, Salonen JT: Childhood and adult socio-economic status as predictors of mortality in Finland. Lancet 1994, 343(8896):524-527.

15. Espelt A, Borrell C, Roskam AJ, Rodríguez-Sanz M, Stirbu I, Dalmau-Bueno A, Regidor E, Bopp M, Martikainen P, Leinsalu M, Artnik B, Rychtarikova J, Kalediene R, Dzurova D, Mackenbach J, Kunst AE: Socioeconomic inequalities in diabetes mellitus across Europe at the beginning of the 21st century. Diabetologia 2008, 51(11):1971-1979.

16. Dietz WH: Critical periods in childhood for the development of obesity. Am J Clin Nutr 1994, 59(5):955-959.

17. Kempf K, Rathmann W, Herder C: Impaired glucose regulation and type 2 diabetes in children and adolescents. Diab Metab Res Rev 2008, 24(6):427-437.

18. Lawlor DA, Ebrahim S, Davey Smith G: Socioeconomic position in childhood and adulthood and insulin resistance: cross sectional survey using data from British women's heart and health study. BMJ 2002, 325(7368):805

19. Lawlor DA, Harro M, Wedderkopp N: Association of socioeconomic position with insulin resistance among children from Denmark, Estonia, and Portugal: cross sectional study. BMJ 2005, 331(7510):183-187.

20. Agardh EE, Ahlbom A, Andersson T, Efendic S, Grill V, Hallqvist J, Ostenson CG: Socio-economic position at three points in life in association with type 2 diabetes and impaired glucose tolerance in middle-aged Swedish men and women. Int J Epidemiol 2007, 36(1):84-92

21. Ebrahim S, Montaner D, Lawlor DA: Clustering of risk factors and social class in childhood and adulthood in British women's heart and health study: cross sectional analysis. BMJ 2004, 328(7444):861.

22. Goran MI, Ball GD, Cruz ML: Obesity and risk of type 2 diabetes and cardiovascular disease in children and adolescents. J Clin Endocrinol Metab 2003, 88(4):1417-1427.

23. Sobal J, Stunkard AJ: Socioeconomic status and obesity: a review of the literature. Psychol Bull 1989, 105(2):260-275.

24. Felitti VJ, Anda RF, Nordenberg D, Williamson DF, Spitz AM, Edwards V, Koss MP, Marks JS: Relationship of Childhood Abuse and Household Dysfunction to Many of the Leading Causes of Death in Adults: The Adverse Childhood Experiences (ACE) Study. Am J Prev Med 1998, 14(4):245-258.
25. Antonovsky A: Unravelling the Mystery of Health: How People Manage Stress and Stay Well. San Francisco: Jossey-Boss 1987.

26. Carstairs V: Deprivation indices: their interpretation and use in relation to health. J Epidemiol Community Health 1995, 49(Suppl 2):S3-8.

27. Diez Roux AV, Jacobs DR, Kiefe Cl: Neighborhood characteristics and components of the insulin resistance syndrome in young adults: the coronary artery risk development in young adults (CARDIA) study. Diabetes Care 2002, 25(11):1976-1982.

28. Stroup DF, Berlin JA, Morton SC, Olkin I, Williamson GD, Rennie D, Moher D, Becker BJ, Sipe TA, Thacker SB: Meta-analysis of observational studies in epidemiology: a proposal for reporting. Meta-analysis Of Observational Studies in Epidemiology (MOOSE) group. JAMA 2000 283(15):2008-2012

29. Chida Y, Hamer M: An association of adverse psychosocial factors with diabetes mellitus: a meta-analytic review of longitudinal cohort studies. Diabetologia 2008, 51(12):2168-2178.

30. Karlberg J: A biologically-oriented mathematical model (ICP) for human growth. Acta Paediatr Scand 1989, 350:70-94.

31. Lammi N, Moltchanova E, Blomstedt PA, Tuomilehto J, Eriksson JG, Karvonen M: Childhood BMI trajectories and the risk of developing young adult-onset diabetes. Diabetologia 2009, 52(3):408-414.

32. Expert Committee on the Diagnosis and Classification of Diabetes Mellitus: Report of the Expert Committee on Diagnosis and Classification of Diabetes Mellitus. Diabetes Care 1997, 20(7):1183-1194.

33. Manson JE, Colditz GA, Stampfer MJ: A prospective study of maturityonset diabetes mellitus and risk of coronary heart disease and stroke in women. Arch Intern Med 1991, 151(6):1141-1147.

34. Field AE, Coakley EH, Must A, Spadano JL, Laird N, Dietz WH, Rimm E, Colditz GA: Impact of overweight on the risk of developing common chronic diseases during a 10-year period. Arch Intern Med 2001, 161(13):1581-1586

35. Likhari T, Aulakh TS, Singh BM, Gama R: Does HbA1C predict isolated impaired fasting glycaemia in the oral glucose tolerance test in subjects with impaired fasting glycaemia? Ann Clin Biochem 2008, 45(4):418-420.

36. Kilpatrick ES: HbA1c of glucose for diabetes diagnosis? Ann Clin Biochem 2005, 42(3):165-166.

37. Yudkin JS, Forrest RD, Jackson CA, Ryle AJ, Davie S, Gould BJ: Unexplained variability of glycated haemoglobin in non-diabetic subjects not related to glycemia. Diabetologia 1990, 33(4):208-215.

38. Snieder H, Sawtell PA, Ross L, Walker J, Spector TD, Leslie RD: HbA1c levels are genetically determined even in type 1 diabetes: evidence from healthy and diabetic twins. Diabetes 2001, 50(12):2858-2863.

39. Barakat $\mathrm{O}$, Krishnan ST, Dhatariya K: Falsely low HbA1c value due to a rare variant of hemoglobin J-Baltimore. Prim Care Diabetes 2008, 2(3):155-157.

40. Maty SC, James SA, Kaplan GA: Life-course socioeconomic position and incidence of diabetes mellitus among blacks and whites: the Alameda County Study, 1965-1999. Am J Public Health 2010, 100(1):137-45.

41. Lidfeldt J, Li TY, Hu FB, Manson JE, Kawachi I: A prospective study of childhood and adult socioeconomic status and incidence of type 2 diabetes in women. Am J Epidemiol 2007, 165(8):882-889.

42. Maty SC, Lynch JW, Raghunathan TE, Kaplan GA: Childhood socioeconomic position, gender, adult body mass index, and incidence of type 2 diabetes mellitus over 34 years in the Alameda County Study. Am J Public Health 2008, 98(8):1486-1494.

43. Gissler M, Rahkonen $\mathrm{O}$, Järvelin MR, Hemminki E: Social class differences in health until the age of seven years among the finnish 1987 birth cohort. Soc Sci Med 1998, 46(12):1543-1552.

44. Kohler IV, Soldo BJ: Childhood predictors of late-life diabetes: the case of Mexico. Soc Biol 2005, 52(3-4):112-131.

45. Best LE, Hayward MD, Hidajat MM: Life course pathways to adult-onset diabetes. Soc Biol 2005, 52(3-4):94-111.

46. Kivimäki $M$, Smith $G D$, Juonala $M$, Ferrie JE, Keltikangas-Järvinen $L$, Elovainio M, Pulkki-Råback L, Vahtera J, Leino M, Viikari JS, Raitakari OT: Socioeconomic position in childhood and adult cardiovascular risk factors, vascular structure, and function: cardiovascular risk in young Finns study. Heart 2006, 92(4):474-480.

47. Langenberg C, Kuh D, Wadsworth ME, Brunner E, Hardy R: Social circumstances and education: life course origins of social inequalities in metabolic risk in a prospective national birth cohort. Am J Public Health 2006, 96(12):2216-2221 
48. Thomas C, Hypponen E, Power C: Obesity and type 2 diabetes risk in midadult life: the role of childhood adversity. Pediatrics 2008, 121(5):1240-1249.

49. Hayes L, Pearce MS, Unwin NC: Lifecourse predictors of normal metabolic parameters in overweight and obese adults. Int J Obes (Lond) 2006, 30(6):970-976

50. Goodman E, Daniels SR, Dolan LM: Socioeconomic disparities in insulin resistance: results from the Princeton School District Study. Psychosom Med 2007, 69(1):61-67.

51. Edwards AM: Classification of occupations. J Am Stat Assoc 1911, 12:618-646.

52. Statistics Finland: Classification of socioeconomic groups 1989. Statistics Finland 1989 Handbooks 17, Helsinki [http://www.stat.fi/meta/luokitukset/ ammatti/001-2001/koko_luokitus_en.html], assessed 20 may 2009.

53. British Registrar General's Scale, adapted from Stevenson THC: The Vital Statistics of Wealth and Poverty. J R Stat Soc 1928, 91:207-230.

54. Novak M, Ahlgren C, Hammarström A: A life-course approach in explaining social inequity in obesity among young adult men and women. Int J Obes (Lond) 2006, 30(1):191-200.

55. Power C, Manor O, Matthews S: Child to adult socioeconomic conditions and obesity in a national cohort. Int J Obes Relat Metab Disord 2003, 27(9):1081-1086.

56. Laitinen J, Power C, Jarvelin MR: Family social class, maternal body mass index, childhood body mass index, and age at menarche as predictors of adult obesity. Am J Clin Nutr 2001, 74(3):287-294.

57. Salsberry PJ, Reagan PB: Taking the long view: the prenatal environment and early adolescent overweight. Res Nurs Health 2007, 30(3):297-307.

58. Dubois L, Girard M: Early determinants of overweight at 4.5 years in a population-based longitudinal study. Int J Obes (Lond) 2006, 30(4):610-617.

59. Howe LD, Galobardes B, Sattar N, Hingorani AD, Deanfield J, Ness AR, Davey-Smith G, Lawlor DA: Are there socioeconomic inequalities in cardiovascular risk factors in childhood, and are they mediated by adiposity? Findings from a prospective cohort study. Int J Obes (Lond) 2010.

60. Koupil I, Toivanen P: Social and early-life determinants of overweight and obesity in 18-year-old Swedish men. Int J Obes (Lond) 2008, 32(1):73-81.

61. Strauss RS, Knight J: Influence of the home environment on the development of obesity in children. Pediatrics 1999, 103(6):e85.

62. Gordon-Larsen P, Adair LS, Suchindran CM: Maternal obesity is associated with younger age at obesity onset in U.S. adolescent offspring followed into adulthood. Obesity (Silver Spring) 2007, 15(11):2790-2796.

63. Bradley RH: Children's home environments, health, behavior and intervention efforts: a review using the HOME inventory as a marker measure. Genet Soc Gen Psychol Monogr 1993, 119(4):439-490.

64. Bradley RH: The HOME inventory: review and reflections. Adv Child Dev Behav 1994, 25:242-288.

65. Kristensen PL, Wedderkopp N, Møller NC, Andersen LB, Bai CN, Froberg K: Tracking and prevalence of cardiovascular disease risk factors across socio-economic classes: a longitudinal substudy of the European Youth Heart Study. BMC Public Health 2006, 6:20.

66. Elgar FJ, Roberts C, Moore L, Tudor-Smith C: Sedentary behaviour, physical activity and weight problems in adolescents in Wales. Public Health 2005, 119(6):518-524.

67. Giskes K, van Lenthe FJ, Turrell G, Kamphuis CB, Brug J, Mackenbach JP: Socioeconomic position at different stages of the life course and its influence on body weight and weight gain in adulthood: a longitudina study with 13-year follow-up. Obesity (Silver Spring) 2008, 16(6):1377-1381.

68. Lee H, Harris KM, Gordon-Larsen P: Life Course Perspectives on the Links Between Poverty and Obesity During the Transition to Young Adulthood. Popul Res Policy Rev 2009, 28(4):505-532.

69. Balistreri KS, Van Hook J: Socioeconomic status and body mass index among Hispanic children of immigrants and children of natives. Am J Public Health 2009, 99(12):2238-2246.

70. Engum $\mathrm{A}$ : The role of depression and anxiety in onset of diabetes in a large population-based study. J Psychosom Res 2007, 62(1):31-38

71. Eaton WW, Armenian H, Gallo J, Pratt L, Ford DE: Depression and risk for onset of type II diabetes. A prospective population-based study. Diabetes Care 1996, 19(10):1097-1102.

72. Räikkönen K, Matthews KA, Salomon K: Hostility predicts metabolic syndrome risk factors in children and adolescents. Health Psychology 2003, 22(3):279-286.
73. Kouvonen AM, Väänänen A, Woods SA, Heponiemi T, Koskinen A, Toppinen-Tanner S: Sense of coherence and diabetes: a prospective occupational cohort study. BMC Public Health 2008, 8:46.

74. Cox M, Boyle PJ, Davey P, Morris A: Does health-selective migration following diagnosis strengthen the relationship between Type 2 diabetes and deprivation? Soc Sci Med 2007, 65(1):32-42

75. Schootman M, Andresen EM, Wolinsky FD, Malmstrom TK, Miller JP, Yan Y, Miller DK: The effect of adverse housing and neighborhood conditions on the development of diabetes mellitus among middle-aged African Americans. Am J Epidemiol 2007, 166(4):379-387.

76. Wilsgaard T, Jacobsen BK: Lifestyle factors and incident metabolic syndrome. The Tromsø Study 1979-2001. Diabetes Res Clin Prac 2007, 78(2):217-224.

77. Perkonigg A, Owashi T, Stein MB, Kirschbaum C, Wittchen HU: Posttraumatic stress disorder and obesity: evidence for a risk association. Am J Prev Med 2009, 36(1):1-8.

78. Coogan PF, Cozier YC, Krishnan S, Wise LA, Adams-Campbell LL, Rosenberg L, Palmer JR: Neighborhood Socioeconomic Status in Relation to 10-Year Weight Gain in the Black Women's Health Study. Obesity (Silver Spring) 2010

79. Koch FS, Sepa A, Ludvigsson J: Psychological stress and obesity. J Pediatr 2008, 153(6):839-44.

80. Robinson WR, Stevens J, Kaufman JS, Gordon-Larsen P: The Role of Adolescent Behaviors in the Female-Male Disparity in Obesity Incidence in US Black and White Young Adults. Obesity (Silver Spring) 2009.

81. Liberatos $P$, Link BG, Kelsey JL: The measurement of social class in epidemiology. Epidemiol Rev 1988, 10:87-121.

82. Liem ET, Sauer PJ, Oldehinkel AJ, Stolk RP: Association between depressive symptoms in childhood and adolescence and overweight in later life: review of the recent literature. Arch Pediatr Adolesc Med 2008, 162(10):981-988

83. Knol MJ, Twisk JW, Beekman AT, Heine RJ, Snoek FJ, Pouwer F: Depression as a risk factor for the onset of type 2 diabetes mellitus. A metaanalysis. Diabetologia 2006, 49(5):837-845.

84. Brown LC, Majumdar SR, Newman SC, Johnson JA: History of depression increases risk of type 2 diabetes in younger adults. Diabetes Care 2005, 28(5):1063-1067

85. Turner RJ, Wheaton B, Lloyd DA: The epidemiology of social stress. Am Sociol Rev 1995, 60:104-125

86. Pouwer F, Kupper N, Adriaanse MC: Does emotional stress cause type 2 diabetes mellitus? A review from the European Depression in Diabetes (EDID) Research Consortium. Discov Med 2010, 9(45):112-118.

87. Laitinen J, Power C, Ek E, Sovio U, Järvelin MR: Unemployment and obesity among young adults in a northern Finland 1966 birth cohort. Int J Obes Relat Metab Disord 2002, 26(10):1329-1338.

88. Lehman BJ, Taylor SE, Kiefe Cl, Seeman TE: Relation of childhood socioeconomic status and family environment to adult metabolic functioning in the CARDIA study. Psychosom Med 2005, 67(6):846-854.

89. Bourdieu P: La distinction. Critique sociale du jugement. Éditions de Minuit. Paris 1979.

90. Taylor SE, Stanton AL: Coping resources, coping processes, and mental health. Annu Rev Clin Psychol 2007, 3:377-401.

91. Sallis JF, Saelens BE, Frank LD, Conway TL, Slymen DJ, Cain KL, Chapman JE, Kerr J: Neighborhood built environment and income: examining multiple health outcomes. Soc Sci Med 2009, 68(7):1285-1293.

92. Veugelers $P$, Sithole F, Zhang S, Muhajarine N: Neighborhood characteristics in relation to diet, physical activity and overweight of Canadian children. Int J Pediatr Obes 2008, 3(3):152-159.

93. Sergeant JC, Firth D: Relative index of inequality: definition, estimation, and inference. Biostatistics 2006, 7:213-224.

\section{Pre-publication history}

The pre-publication history for this paper can be accessed here: http://www.biomedcentral.com/1471-2458/10/525/prepub

doi:10.1186/1471-2458-10-525

Cite this article as: Tamayo et al:: Impact of early psychosocial factors (childhood socioeconomic factors and adversities) on future risk of type 2 diabetes, metabolic disturbances and obesity: a systematic review. BMC Public Health 2010 10:525. 